\title{
A COMUNICACIÓN ORGANIZACIONAL NOS CONCELLOS GALEGOS (1939-2004)
}

\section{Berta García Orosa}

\section{INTRODUCIÓN}

No marco dunha democracia potencialmente deliberativa, os diferentes actores sociais loitan por acadar ou consolidar un lugar na opinión pública que reforce o seu status quo. Neste proceso tamén interveñen as administracións públicas que, ademais de ter a obriga legal de informar o cidadán, participan no «mercado da información». O papel fundamental dos medios de comunicación como xestores da «vontade popular»e, sobre todo, a modificación dos roles e da relación entre poder político local e medios de comunicación serán analizados no relatorio proposto.

Os datos presentados son froito dunha investigación cuantitativa e cualitativa realizada a través de 1500 enquisas e un total de 22 entrevistas en profundidade cos responsables e traballadores de gabinetes de comunicación. O marco espacial do estudo presentado é a comunidade autónoma galega.

\section{BREVE APROXIMACIÓN HISTÓRICA}

A comunicación organizacional dentro da comunidade autónoma galega debe ser contextualizada en dous grandes ámbitos: a) social: a dos poderes hexemónicos da sociedade que intentan ter presenza positiva na opinión pública e b) normativa: dende a chegada da democracia os poderes públicos teñen a obriga de ser transparentes ante o cidadán.

Neste marco, a comunicación organizacional foi avanzando a medida que evolucionaba o novo sistema político e, polo tanto, social en España. Deste xeito, a grandes trazos podemos indicar os seguintes momentos da comunicación organizacional nas administracións locais ${ }^{1}$ :

1. Para a explicación da evolución histórica actualizaremos a proposta de Pasqual Maragall en 1993. 
En primeiro lugar, situamos o período 1939-1975. Os concellos no período franquista, como tantas outras institucións, estaban gobernados por alcaldes nomeados aleatoriamente e concelleiros que normalmente estaban ligados aos grupos económicos dominantes nas cidades ou na burocracia do propio réxime. Polo tanto, os gobernos locais carecían da lexitimidade democrática e a planificación e aplicación das políticas públicas favorecían o status quo existente.

Nestes anos, nos concellos, igual que no resto de sectores en España, existía unha gran desinformación xa que o réxime de Francisco Franco non recoñecía a liberdade de expresión. A información promovida pola Administración pública era controlada e difundida por uns medios de comunicación que carecían de liberdade para a interpretación e inclusión de temas na axenda de información. Por suposto, o concepto de comunicación local galega estaba absolutamente solapado.

En segundo lugar, debemos facer referencia ao período 1975-1979, no que se recuperan as liberdades democráticas. Os primeiros comicios xerais tras a morte de Francisco Franco realizáronse o 15 de xuño de 1977. Os primeiros concellos democráticos, en cambio, non se constituíron ata a primavera de 1979. Durante dous anos conviviron en España un parlamento elixido democraticamente, un goberno saído desas eleccións e uns partidos políticos legalizados que coexistían con alcaldes e concelleiros nomeados por Franco ou a través de procedementos franquistas. Isto provocaba que carecesen de autoridade moral e lexitimidade democrática².

Evidentemente, nesta situación a comunicación segue a ser informal e lonxe está a posibilidade de creación de gabinetes de comunicación institucionais. Lembremos que falamos dun país onde pedir opinión aos cidadáns para a realización de políticas públicas podería non estar ben considerado.

En terceiro lugar, o período 1979-1987, que está presidido pola loita dos concellos para conseguir que se considerase como 
unha cuestión de Estado a resolución dos graves problemas de financiamento que afectaban aos municipios. Ademais, nesta etapa a formación do novo réxime político polarizouse arredor da construción, por un lado, dunha Administración central moderna e tecnificada e, polo outro, do novo poder das rexións e nacionalidades autónomas. No medio dos dous grandes protagonistas da transición, os concellos tiveron que traballar firme para manter as súas competencias e reclamar os medios necesarios para exercelas. Todo isto obrigou os alcaldes a complementar a súa actividade normal de xestores de representantes das súas cidades coa de defensores do rol dos concellos na mellora do servizo público, na construción daquela nova colectividade que se tiña como proxecto.

Isto reflíctese no desenvolvemento da comunicación organizacional en España. Durante esta etapa créase o 20\% dos departamentos de comunicación que na actualidade existen en administracións locais en España. Eran, normalmente, pequenas organizacións dentro dos concellos, con persoal irregularmente profesionalizado e incluídos fundamentalmente nas administracións locais de maiores dimensións. Galicia, seguindo a tendencia sinalada, rexistra un gran desenvolvemento nesta época, coa creación do 42,85\% dos gabinetes de comunicación.

$\mathrm{Na}$ etapa que podemos sinalar como cuarta, 1987-1993, temos dous referentes comúns: a «consolidación» do estado das autonomías e a referencia da construción de Europa. A Europa da que nos ocupamos é por excelencia a Europa das cidades. A cidade é un enxeño, un artefacto europeo. O que entendemos por cidade empeza sendo basicamente unha creación grega que a cultura romana reformula. Coa organización medieval, a cidade reasume o seu protagonismo e encarna unha vontade de independencia, de autonomía e de liberalidade. Entre os factores que se acrisolaron coa formación da Europa actual, a cidade desempeña indiscutiblemente un papel destacado como legado da nosa cultura, como cristalización da temporalidade histórica de Europa, como patrimonio que anoa os lazos de relación entre o noso pasado e as expectativas que determinan o horizonte do noso futuro co presente que acotío vivimos. 
Durante esta época, en España créanse o 25\% dos departamentos de comunicación que existen na actualidade e poténciase a profesionalización dos existentes anteriormente. No caso de Galicia, cun ritmo máis lento, constitúese o 14,28\%.

Na última década, entre 1993 e 2004, podemos falar do desenvolvemento e da consolidación en Galicia e España da comunicación organizacional no ámbito local. O 55\% dos actuais gabinetes de comunicación das poboacións de máis de 20000 habitantes e o $42,85 \%$ do global das administracións locais en España constituíronse neste período, porcentaxe similar á do caso galego.

Polo tanto, cronoloxicamente observamos unha evolución similar en Galicia e no resto de España, marcada sobre todo pola propia evolución da transferencia de competencias e recursos, e en definitiva poder, aos concellos. Neste sentido o gran desenvolvemento aparece sobre todo a partir do ano 2000 (o 55\% dos gabinetes de comunicación en Galicia xorden a partir de 1993).

3 PANORAMA DA COMUNICACIÓN ORGANIZACIONAL NA ADMINISTRACIÓN LOCAL NA COMUNIDADE AUTÓNOMA

Pero, que caracteriza os gabinetes de comunicación da Administración local fronte aos outros? Nas próximas liñas exporemos unha breve visión dos departamentos de comunicación.

En primeiro lugar, non podemos esquecer a obriga legal que teñen todas as administracións públicas de informar o cidadán e tampouco as características propias da comunicación local.

Neste contexto, a maioría defínense como «gabinete de comunicación» aínda que en moitos casos -especialmente nas localidades más pequenas- a actividade única é a relación cos medios de comunicación. Esta ausencia de coincidencia entre a actividade e a súa definición xa é sintomática dunha situación en que existe non só unha indefinición conceptual (a de comunicación) senón tamén de poderes. A comunicación nos concellos galegos comeza normalmente como unha actividade vinculada ao departamento de cultura ou de atención ao cidadán e continúa na actualidade realizando tarefas escasamente definidas. 


\section{Tipo de gabinete}

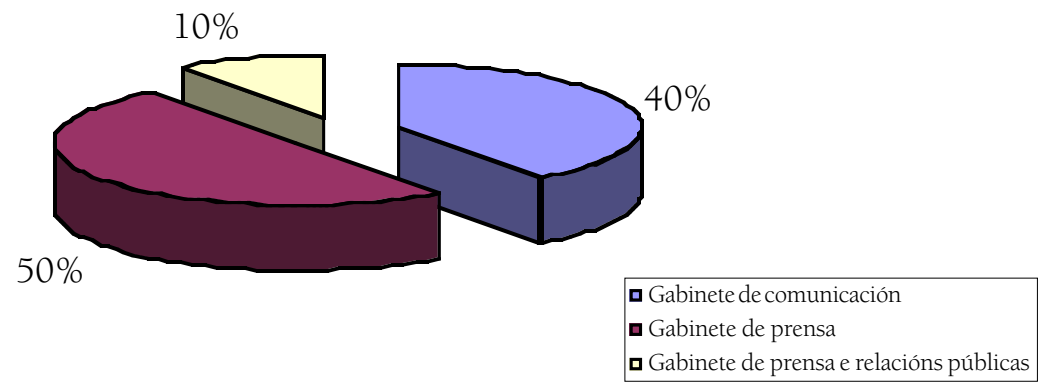

Dentro do primeiro sector (a Administración pública), a lectura da porcentaxe de concellos con departamento de comunicación é moi inferior á doutras institucións do eido público. Neste sentido, mentres que a Administración autonómica e as delegacións do Estado en Galicia rozan o 100\%, a local unicamente rexistra un $6,62 \%$ de concellos con gabinete de comunicación.

A situación é similar no conxunto de España. Neste caso, a media do sector é do $80 \%$, e no caso da Administración local debemos falar dun 69,36\% nos concellos con máis de 20000 habitantes e dun 15\% nos concellos con menos de 20000 habitantes.

Polo tanto, dentro das administracións públicas, o espazo virxe no eido da comunicación, polo momento, son os concellos.

Estes gabinetes de comunicación en Galicia están caracterizados, na súa maioría, por unha indefinición de funcións, unha escaseza de recursos (case 8 de cada 10 son unipersoais) e, polo tanto, pola restrición das súas funcións á comunicación externa (78\% só comunicación externa) e concretamente á relación cos medios de comunicación. A planificación e a aplicación de políticas comunicativas redúcese, deste xeito, ao intento continuo de obter unha presenza cuantitativa e positiva nos medios. 


\section{Tipo de comunicación}

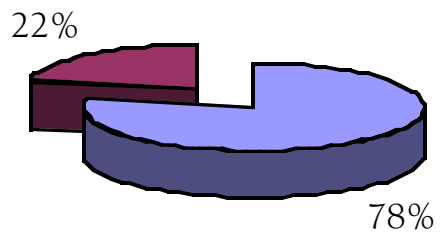

口 Comunicación externa

a Comunicación externa e interna

Traballadores do gabinete

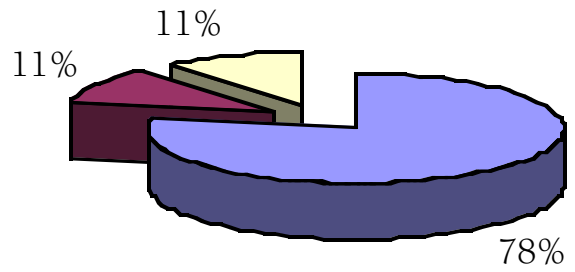

- Unipersonal

- Dúas persoas

- Máis de dúas persoas

4 PERSPECTIVAS DE FUTURO

Dende as primeiras eleccións democráticas comezaron a xurdir as primeiras xestións organizadas de accións comunicativas nos concellos locais e os gabinetes de prensa dos concellos multiplicáronse en Galicia a partir sobre todo do segundo mandato municipal (1983-1987), tendencia similar á rexistrada no resto de España $a^{3}$ O cambio de estratexia, dende o secreto á transparencia obrigada legalmente ${ }^{4}$, perfila o seu principal obxectivo como o de ter eco nos medios de comunicación e permitir aos cidadáns obter a información sobre o labor desenvolvido polo concello e, en segundo lugar, a resposta ás demandas informativas dos medios de

3. Pérez González, R.A., Un modelo estratégico de comunicación municipal, tese de doutoramento, Madrid, Universidad Complutense, 1988.

4. Pérez Varela, Jesús, «La comunicación política en el sistema democrático», en VV.AA., La comunicación política, Pontevedra, Deputación de Pontevedra, 1996. 
comunicación, cada vez máis interesados nunha comunicación directa co seu público e a transmisión de información próxima que lles garanta a supervivencia nun mundo comunicativo cada vez máis globalizado.

Picos Freire 5 indica que foron as corporacións locais, e incluso antes de ter unha lei que recollera os aspectos de participación e comunicación, as pioneiras en lanzarse a desenvolver sistemas de información próxima.

Non obstante, a información local é un arma de dous fíos xa que, se ben é a canle de comunicación dos cidadáns cos seus representantes, pode converterse en fonte de información interesada. Para evitalo, a solución é a profesionalización. Neste sentido, María Luisa Cárdenas afirma que os gabinetes de comunicación teñen que ser apolíticos e servir á prensa, aos cidadáns e non a un partido político ${ }^{7}$. No caso de Galicia, a precariedade laboral, a ausencia de profesionalización e a característica de «posto de confianza» do persoal de comunicación dificultan a elaboración dun traballo non personalizado -dirixido ao líder ou ao grupo líder-e aséptico. A propia definición do posto de traballo e localización do gabinete dentro da institución indican a finalidade do seu labor.

Neste sentido, consideramos que habería que facer unha descrición do posto de traballo e oposición pública, como ocorreu en determinados concellos.

A característica de funcionarios de oposición garante unha estancia no servizo moito máis longa, o que redunda nun maior coñecemento das estruturas administrativas nas que traballan. A estabilidade do citado servizo e o mantemento das súas normas de

5. Picos Freire, José J., «Estructura de la prensa local en España», en VV.AA.: Manual de periodismo, Barcelona, Prensa Ibérica, 1995.

6. Cárdenas Rica, María Luisa, «Profesionalización de los gabinetes de prensa locales», Revista Latina de Comunicación Social, La Laguna (Tenerife), marzo 1999, n. ${ }^{\circ} 15$. (www.ull.es/publicaciones/latina/a1999c/117luisa.htm) ou en Ámbitos 1/Revista Andaluza de Comunicación, Sevilla, 1998, 131-141.

7. Cárdenas Rica, María Luisa, «Profesionalización de los gabinetes de prensa locales», en Revista Latina de Comunicación social, La Laguna (Tenerife), marzo 1999, n. ${ }^{\circ} 15$. (www.ull.es/publicaciones/latina/a1999c/117luisa.htm) ou en Ámbitos 1/Revista Andaluza de Comunicación, Sevilla, 1998. 
funcionamento e contidos xeran confianza nos medios de comunicación, fan diminuír os receos habituais ante unha información procedente dun gabinete de prensa, o que produce unha visión máis coherente e global do que é a institución pública e evita o distanciamento da actualidade puramente política respecto do conxunto da entidade institucional ${ }^{8}$.

A figura do Dircom no espazo local aínda está sen definir, aínda que oscila, igual que nos outros casos, entre un simple transmisor de información e un actor dentro e/ou fóra da entidade.

A pesar de seren os concellos historicamente as esferas fundamentais de participación cidadá na vida política e social, o gabinete de comunicación non constitúe aínda o vehículo fundamental desta interacción.

8. Carmona Salinas, J.F., «El servicio de comunicación profesionalizado en una institución pública. El caso del Gobierno de Navarra», en II Congreso de Comunicación Corporativa. La comunicación en las economías inteligentes, Madrid, ACEI, outubro 1996. 


\section{REFERENCIAS BIBLIOGRÁFICAS}

Blumler, J. e Gurevitch, M., The crisis of public communication, London, Routledge, 1995.

CÁRdenAs RicA, M. L., «Profesionalización de los gabinetes de prensa locales», Revista Latina de Comunicación Social, La Laguna (Tenerife), marzo 1999, n. ${ }^{\circ} 15$ (www.ull.es/publicaciones/ latina/a1999c/117luisa.htm) ou en Ámbitos 1/Revista Andaluza de Comunicación, Sevilla, 1998.

Carmona Salinas, J. F., «El servicio de comunicación profesionalizado en una institución pública. El caso del Gobierno de Navarra», en II Congreso de Comunicación Corporativa. La comunicación en las economías inteligentes, Madrid, ACEI, outubro 1996.

CRuz Mundet, J. R., Información y documentación administrativa, Madrid, Tecnos, 1998.

García Rubio, F., Las nuevas tecnologías ante el Derecho y la organización administrativa, Madrid, Ministerio de Administraciones Públicas, 2003.

Maragall, P., Los ayuntamientos, Barcelona, Editorial Destino, 1997.

Martínez Bargueño, R., Teoría y práctica de la información administrativa al ciudadano, Madrid, INAP, 1987.

Parckard, V., Las formas ocultas de la propaganda, Buenos Aires, Ed. Sudamericana, 1967.

Pérez GonzÁlez, R. A., Un modelo estratégico de comunicación municipal, tese de doutoramento, Madrid, Universidad Complutense, 1988.

Pérez VARela, J., «La comunicación política en el sistema democrático», en VV.AA., La comunicación política, Pontevedra, Deputación de Pontevedra, 1996. 
Picos Freire, J. J., «Estructura de la prensa local en España», en VV.AA.: Manual de periodismo, Barcelona, Prensa Ibérica, 1995.

Téllez Aguilera, A., Nuevas tecnologías. Intimidad y protección de datos, Madrid, Edisofer, 2001.

Tornos mas, J. e Galán Galán, A., Comunicación pública. La información administrativa al ciudadano, Madrid, Marcial Pons, 2000 .

WeIL, G., La comunicación global: comunicación institucional y de gestión, Barcelona, Paidós, 1992.

WhitAKer, R., El fin de la privacidad. Cómo la vigilancia total se está convirtiendo en realidad, Barcelona, Paidós, 1999. 